ADVERSE SELECTION IN DURABLE GOODS MARKETS

Igal Hendel

Alessandro Lizzeri

Working Paper 6194 
NBER WORKING PAPER SERIES

\title{
ADVERSE SELECTION IN DURABLE GOODS MARKETS
}

\author{
Igal Hendel \\ Alessandro Lizzeri
}

Working Paper 6194

http://www.nber.org/papers/w6194

\author{
NATIONAL BUREAU OF ECONOMIC RESEARCH \\ 1050 Massachusetts Avenue \\ Cambridge, MA 02138 \\ September 1997
}

We would like to thank Pierpaolo Battigalli and seminar audiences at Caltech, the Hebrew University, New York University, Tel Aviv University, UCLA, and Yale University. Financial support for this project by National Science Foundation grant SBR-9711355 is gratefully acknowledged. This paper is part of NBER's research program in Industrial Organization. Any opinions expressed are those of the authors and not those of the National Bureau of Economic Research.

(C) 1997 by Igal Hendel and Alessandro Lizzeri. All rights reserved. Short sections of text, not to exceed two paragraphs, may be quoted without explicit permission provided that full credit, including $(\mathcal{C}$ notice, is given to the source. 
Adverse Selection in Durable Goods Markets

Igal Hendel and Alessandro Lizzeri

NBER Working Paper No. 6194

September 1997

JEL Nos. D82, L15

Industrial Organization

\section{ABSTRACT}

An undesirable feature of Akerlof style models of adverse selection is that ownership of used cars is independent of preferences and is therefore ad hoc. We present a dynamic model that incorporates the market for new goods. Consumers self-select into buying new or used goods making ownership of used goods endogenous. We show that, in contrast with Akerlof and in agreement with reality, the used market never shuts down and that the volume of trade can be quite substantial even in cases with severe informational asymmetries. By incorporating the market for new goods, the model lends itself to a study of the effects of adverse selection on manufacturers' incentives. We find that manufacturers may gain from adverse selection. We also give an example in which the market allocation under adverse selection is socially optimal. An extension of the model to a world with many brands that differ in reliability leads to testable predictions of the effects of adverse selection. We show that unreliable car brands have steeper price declines and lower volumes of trade.

Igal Hendel

Department of Economics

Princeton University

Princeton, NJ 08544

and NBER

igal@princeton.edu
Alessandro Lizzeri

Department of Economics

Princeton University

Princeton, NJ 08544

lizzeri@princeton.edu 


\section{Introduction}

Investment, consumption and production of durable goods represent a large fraction of economic activity in all industrialized economies. In his seminal paper, Akerlof (1970) suggested that resale markets for durable goods may be subject to adverse selection: first owners of a durable good such as cars learn more about the quality of the good than a buyer can potentially find out prior to purchase. Akerlof showed that this asymmetry of information is a source of inefficiency and can even produce a complete shut down of the market preventing beneficial transactions altogether.

As a model of adverse selection in markets for durable goods, Akerlof's is incomplete. Consider the following typical example. ${ }^{1}$ There are two types of consumer: one type values $v$ a car of quality $v$, the other type values it at $1.5 v$. The the low valuation consumer is the owner, the high valuation consumer is a potential buyer. Quality $v$ is distributed uniformly on $[0,1]$, the owner knows $v$ the buyer does not. Clearly efficiency requires that all cars be traded but there is no price that generates any trade at all: the unique equilibrium involves no trade. Thus the market breaks down despite the fact that it is common knowledge that the potential buyer values the car more. The inefficiency comes from the fact that the owner of the car is the low valuation consumer. We have to ask whether this is a relevant case. Most people are not born owning a used car, if they own one it is because they bought a new car in the past. ${ }^{2}$ But the high valuation consumer presumably could also try to buy the new car. How is it that the low valuation consumer gets to buy the new car and we end up with the "wrong" distribution of ownership at the time the used market opens? The incompleteness of Akerlof's model stems from the absence of the market for new goods.

More generally, in standard models of adverse selection (Akerlof (1970), Wilson (1980)) the distribution of ownership is independent of preferences: the used market opens with an ad hoc ownership of cars. However preferences and ownership must be related if there is any persistence over time in the valuations for quality, for example because the intensity of valuation is determined by wealth. Because the market for new goods is not even in the background in these models, it is impossible to study the effects of adverse selection in the used market on the market for new goods. Consequently, we-cannot understand the manufacturers' incentives to respond to adverse selection in the used market by altering their product designs or by contractual solutions.

\footnotetext{
${ }^{1}$ This is essentially Akerlof's original example.

${ }^{2}$ Let's simplify the discussion by assuming that cars only last two periods so that one cannot sell a car that was previously bought used. In any event, at least some of the used car owners must be previous buyers of new cars.
} 
We build a dynamic model of a market where a constant output of new goods goes on sale every period and consumers self-select into buying new or used cars. This creates an endogenous relation between preferences and ownership of used cars. Our results suggest that previous models overstate the distortions caused by adverse selection. We find that the used market never shuts down and that the volume of trade can be quite substantial even in cases of severe information asymmetries. The lowest possible volume of trade when the worst used car is worthless and the best one is as good as a new car. For reasonable parameters the volume of trade in this case ranges between $40 \%$ and $70 \%$. This is a comforting feature of the model since used car markets are very active: the total number of transactions in the used car market in 1996 was more than twice as large as that in the new car market. ${ }^{3}$ The main reason for the higher volume of trade than in Akerlof's model is the different source of gains from trade. Here, just as in real markets for durable goods, an important reason to sell a used car is to enjoy the higher quality offered by a new one. Used car sellers are also new car buyers, consumers who are most sensitive to quality, and have a high opportunity cost of holding on to a lemon. We thus show that taking into account the interactions between the new and the used market considerably lessens the impact of adverse selection.

We also explore the effects of adverse selection on prices. Used car prices fall as a result of adverse selection; this reduces the resale value of new cars. Thus one would expect that adverse selection would depress new car prices. Surprisingly, new car prices can instead be higher under adverse selection than in the absence of quality uncertainty. This is for two reasons. 1) The reduction in the average quality of used goods caused by adverse selection means that the used good is a worse substitute for the new good. 2) In a world with adverse selection a buyer of a new good has an option value because he can keep the high realizations of quality of the used. This phenomenon leads us to believe that manufacturers may benefit from adverse selection. Therefore they may not have an incentive to produce reliable cars.

We then study the welfare effects of adverse selection and identify the distortions caused by asymmetric information. We give an example in which the equilibrium under adverse selection results in the first best allocation, and also show that incentives to trade (e.g. subsidies) can lead to a more inefficient allocation.

Finally we extend the model to an environment with two car brands that differ in the quality dispersion of the used. The high variance (unreliable) brand is more susceptible to adverse selection. We find that the market gets segmented with lower valuation consumers buying the unreliable brand and keeping their cars longer on average. In equilibrium the unreliable brand has steeper price declines and lower volume of trade. This prediction provides

\footnotetext{
${ }^{3}$ Source: "The Automotive Analysis Report", March 1997, Polk Corporation.
} 
a way to test for the presence of adverse selection that relies only on observable data: price and quantity profiles over time and across brands of cars. Casual inspection of price profiles of the most popular cars in the U.S. suggests that the time path of prices presents substantial differences across brands. For example, the price of a three year old Ford Taurus is $\$ 6,800$. This is $\$ 1400$ less than a three year old Honda Accord despite the fact that the new Accord sells for $\$ 2,000 / 3,000$ less than the Taurus. Strikingly, a three year old Honda Civic trades for $\$ 7,400, \$ 600$ more than the Taurus. The new Civic price retails for around $\$ 6,000$ less than the new Taurus. ${ }^{4}$ Our results are consistent with these numbers since Hondas are considered more reliable than Fords. ${ }^{5}$

There is clearly an alternative explanation for these price profiles. It could be that the Taurus has a faster physical depreciation. Our model provides a way to distinguish between these two hypotheses. We show that if the speedier decline is due to faster depreciation the Taurus should have a larger volume of trade. If the difference is due to the Taurus having a bigger lemons problem, then it should have a lower volume of trade than the Honda. ${ }^{6}$

\section{Set-up and Definitions}

We assume that there is an infinite horizon. Time is discrete, and there is a unit mass of consumers that live forever (no new consumers are born). Each consumer demands at most one unit at any date, a consumer of type $\theta$ consuming a sequence of units with qualities $\left(q_{1}, q_{2}, \ldots\right)$ at prices $\left(p_{1}, p_{2}, \ldots\right)$ obtains utility $u(\theta, q, p)=\sum_{t=0}^{\infty} \delta^{t}\left(\theta q_{t}-p_{t}\right) \chi_{t}$ where $\chi_{t}$ is either zero or one depending on whether he consumes in period $t$ or not. We assume that consumers are heterogeneous and represent the distribution of consumer tastes by the cumulative distribution function $F:\left[\theta^{l}, \theta^{h}\right] \rightarrow[0,1]$. With the exception of some numerical examples, we shall assume that $F$ is strictly increasing. The value of $\theta$ is assumed to be unobservable so that trading is anonymous.

We assume that goods last two periods. Since there is an infinite horizon, the markets for new and used goods can always be open simultaneously, and at any date a new car buyer takes into account the future value of a used good. This cannot happen in a two period model. Used markets are potentially open at every date so that consumers can choose to buy new or used goods; if they bought a new good at date $t$ they can choose to sell it at date $t+1$.

\footnotetext{
${ }^{4}$ Used prices are Blue Book trade-in prices for basic model 1994 sedans with 36,000 miles.

${ }^{5}$ Consumer Reports ratings.

${ }^{6}$ To be more precise, in a world with two brands the contrast is made between (1) a case where there is adverse selection and the quality of the used car of one brand has higher variance, and (2) there is symmetric information, transaction costs in the used car market, and the quality of one brand declines faster.
} 
We denote by $v$ the quality of a new good and by $w$ the quality of a used one. Both $v$ and $w$ are assumed to be random variables. However, since the realization of $v$ will be irrelevant, we shall simply denote by $v$ the expectation of the quality of the new product. Let $G(\cdot)$ be the distribution of $w$ with support $\left[w_{l}, w_{h}\right]$. We assume that $G$ is strictly increasing and $w_{h} \leq v$.

Consumer behavior is characterized by a sequence of decisions of what to hold during period $t$ as a function of what they own at the beginning of the period, and as a function of their information: the quality of the car that they own and all observable variables in the market. Thus, if a consumer owns nothing, he can choose to either buy nothing, purchase a new car, or purchase a used car. If the consumer owns a used car, as a function of the quality of the car he owns, he can choose to hold on to the used car or sell it. If he sells it he can choose to either buy nothing, purchase a new car, or purchase a used car.

There is a constant flow of $y$ new units of the product coming on the market at every date. We will ignore how market structure and cost conditions lead to this flow of output to focus on the way this exogenous output is allocated in the presence of used markets and adverse selection. Our characterization of equilibrium, the result on the volume of trade, and the results on two brands do not depend on $y$. The identification of the effects of adverse selection on prices in section 4.4 is interesting even for a fixed $y$ although, as we see in section 4.5 , the relative magnitude of the effects depends on $y$. It is clear that for any $y \leq 1 / 2$ there is going to be some cost level and/or market structure that generates that $y$.

The mass of consumers who get to consume either a new or a used product at any date is at most $2 y$. We shall assume throughout that $y \leq 1 / 2$ so that there are some types who do not consume.

Definition 1 We denote by $\theta_{z}$ the type such that $1-F\left(\theta_{z}\right) \equiv z$.

Thus, $\theta_{z}$ is the type such that there is a mass $z$ of consumers with higher valuation.

\section{Markets with no Asymmetric Information}

Before discussing equilibrium with adverse selection we want to understand the functioning of the model in two benchmark cases where there is no asymmetric information. The two benchmarks will help us evaluate the effects of adverse selection on the functioning of markets. In the first benchmark we assume that there is no quality uncertainty or, equivalently, that there is quality uncertainty but nobody knows the quality so that there is no asymmetric information. In the second benchmark there is quality uncertainty and quality is observable. This is the relevant benchmark for welfare purposes as the equilibrium allocation is first best. 


\subsection{Equilibrium with no Quality Uncertainty}

In the first case we assume $G(\cdot)$ is degenerate at $w<v$. Thus, in this case there is no asymmetric information. An equivalent assumption is that $G(\cdot)$ is non-degenerate but neither the owners of a car nor the potential buyers know anything about the realization of $w$. In the second case, all distributions that have the same mean must lead to the same market allocation. This will not be true in a world where quality is observed by some or all agents. The gains from trade in this environment come from the fact that consumers with higher valuation enjoy consumption of new cars more than those with lower valuation. Thus the former will want to sell their used cars to the latter because they want to buy new cars to upgrade quality.

Given the stationarity of the environment, it is clear that if a consumer is a used car buyer a time $t$ he will be a used car buyer at all dates. Analogously, a new car buyer at date $t$ will be a new car buyer at all dates and therefore never holds on to a used car. In order to see this, consider a consumer who bought a new car at time $t$ and is an owner of a used car when used markets open at date $t+1$. Keeping the used car at date $t+1$ (thus postponing the purchase of a new car) is the same as buying a used car at time $t$ (keeping the used car has the same opportunity cost as buying one). Since the consumer preferred buying a new car at date $t$, he must prefer to sell the used car at date $t+1$ to buy a new car again.

Let $P_{d}^{n}, P_{d}^{u}$ denote the price of new cars and of used cars respectively in this case of degenerate quality. Let $V^{n}(\theta)\left(V^{u}(\theta)\right)$ denote the discounted utility to a consumer of type $\theta$ who buys a new (used) car. By the preceding discussion we have:

$$
\text { (i) } V^{u}(\theta)=\frac{\theta w-P_{d}^{u}}{1-\delta} ;(i i) V^{n}(\theta)=\frac{\theta v-P_{d}^{n}+\delta P_{d}^{u}}{1-\delta}
$$

The discounted utility for buying a new car is obtained from noticing that every period a new car buyer pays a rental price of $P_{d}^{n}-\delta P_{d}^{u}$ for a new car.

For markets to clear we must have that there is a mass of $y$ consumers who buy new cars and a mass of $y$ consumers who buy used cars. Thus the lowest type who buys a new car is type $\theta_{y}$ and the lowest type who buys a used car is type $\theta_{2 y}$. Equilibrium prices can therefore be obtained by setting $V^{u}\left(\theta_{2 y}\right)=0$ and $V^{n}\left(\theta_{y}\right)=V^{u}\left(\theta_{y}\right)$ so that the marginal consumer who buys used is indifferent between buying used and not buying, and the marginal consumer who buys new is indifferent between buying new and buying used.

We thus have:

Proposition 1 In equilibrium all cars are traded in the used market and equilibrium prices are:

$$
P_{d}^{u}=\theta_{2 y} w
$$




$$
P_{d}^{n}=\theta_{y}(v-w)+(1+\delta) \theta_{2 y} w
$$

Remark: (i) The price of a new car has a simple interpretation. Observe that we can rewrite equation 2 as follows: $P_{d}^{n}-P_{d}^{u}=\theta_{y}(v-w)+\delta P_{d}^{u}$. This says that the extra cost of buying the new car is equal to the additional utility of a new car versus a used car for a consumer of type $\theta_{y}$ (the marginal consumer) plus the present value of the resale price.

\subsection{Equilibrium with Observable Quality}

Now we want to consider the market when the distribution of quality of used cars $G(\cdot)$ is nondegenerate but buyers in the used car market observe quality. There is quality uncertainty but no asymmetric information. In this case, an allocation also specifies which types of consumers consume used cars and of what quality. We must therefore define a function $\vartheta:\left[w_{l}, w_{h}\right] \rightarrow\left[\theta^{l}, \theta^{h}\right]$ that specifies that a consumer of type $\vartheta(w)$ consumes a used car of quality $w$.

In equilibrium, types in $\left[\theta^{l}, \theta_{2 y}\right]$ do not buy cars at all, types in $\left[\theta_{2 y}, \theta_{y}\right]$ buy used cars, with lower types consuming lower qualities, and types in $\left[\theta_{y}, \theta^{h}\right]$ buy new cars and trade them after one period. Used markets must clear for every quality $w$. Prices are $P_{o}^{n}$, the price of a new car and a function $P:\left[w_{l}, w_{h}\right] \rightarrow \Re_{+}$that describes the price of every quality of used car.

Proposition 2 In equilibrium all cars are traded in the used market, the function $\vartheta(\cdot)$ is increasing and satisfies $F(\vartheta(w))-F\left(\theta_{2 y}\right)=y G(w) \forall w \in\left[w_{l}, w_{h}\right]$, i.e., higher types consume higher quality and the mass of buyers who consume cars of quality lower than $w$ must equal the mass of existing cars that have a quality below $w$. Equilibrium prices are:

$$
\begin{aligned}
P(w) & =\int_{w_{l}}^{w} \vartheta(s) d s+\theta_{2 y} w_{l} \\
P_{o}^{n} & =\theta_{y}\left(v-w^{h}\right)+\int_{w_{l}}^{w_{h}} \vartheta(s) d s+\delta \int_{w_{l}}^{w_{h}} \int_{w_{l}}^{w} \vartheta(s) d s d G(w)+(1+\delta) \theta_{2 y} w_{l}
\end{aligned}
$$

The proof of this result is in the appendix and uses arguments that are standard in the incentives literature, see Myerson (1981).

Remarks: (i) Once again, the price of a new car has a simple interpretation: $P_{o}^{n}-P\left(w_{h}\right)=$ $\theta_{y}\left(v-w_{h}\right)+\delta E(P(w))$; where $E(P(w))$ is the expected value of the price of a used car. The extra cost of buying the new car relative to a used car of quality $w_{h}$ is equal to the additional 
utility of a new car versus a used car for a consumer of type $\theta_{y}$ plus the present value of the expected resale price. The only difference from the case with observable quality is the fact that the relevant substitute for the marginal consumer of a new car is now a used car of quality $w_{h}$.

(ii) The equilibrium described in Proposition 2 is first best efficient: all types get matched to the right product.

\section{Equilibrium with Adverse Selection}

\subsection{Consumer behavior}

We shall now assume that a customer who buys a new good at date $t$ knows the realization of $w$ at date $t+1$ for the good he bought at date $t$ whereas a buyer who decides to buy a used good does not know the value of $w$ for that good. We assume that there is an infinite number of consumers of each type so that the realized distribution of qualities $w$ owned at the end of a period by each type is $G(\cdot)$.

Let $P^{n}$ denote the price of a new car, and $P^{u}$ the price of a used car. We denote by $w^{u}$ the consumers' beliefs about the average quality of traded used cars. Because of adverse selection, typically we will have that $w^{u}<E(w)$. The average supplied quality, which we shall denote by $w^{A}$, is determined by the selling behavior of owners of used cars. Of course equilibrium requires $w^{u}=w^{A}$, so that in equilibrium expectations are correct. We shall discuss shortly how $w^{A}$ is determined.

Thus consumers take as given the triple $\left(w^{u}, P^{n}, P^{u}\right)$. We first discuss optimal behavior by a consumer given that he is a new car buyer or used car buyer and then determine which consumers will be used car buyers and which ones will be new car buyers.

The behavior of a used car buyer is very simple and is the same as in the case of no quality uncertainty. Define $V^{u}(\theta)$ to be the discounted utility of a consumer of type $\theta$ who buys a used car every period. ${ }^{7}$ Then,

$$
V^{u}(\theta)=\frac{\theta w^{u}-P^{u}}{1-\delta}
$$

The behavior of consumers who contemplate buying new is more complex: such consumers must decide what to do with their used car, they can keep it or sell it. Such decisions depend on the private information of the consumer: the quality of the car $w$ and the intensity of valuation for quality $\theta$.

\footnotetext{
${ }^{7} V^{u}(\theta)$ is also a function of $P^{u}$ and $w^{u}$ but, since this dependence is not exploited until much later, we shall suppress these arguments.
} 
Let $V^{n}(\theta)$ be the discounted utility for a consumer who owns nothing, buys new and then behaves optimally in the used market. ${ }^{8}$

Proposition 3 Optimal behavior for consumers who buy new cars is characterized by a continuous strictly increasing cut-off function $x:\left[\theta^{l}, \theta^{h}\right] \rightarrow\left[w_{l}, w_{h}\right]$ such that a consumer of type $\theta$ sells all used cars of quality below $x(\theta)$ and keeps all those with quality above $x(\theta)$.

$$
x(\theta)=\frac{(1-\delta) V^{n}(\theta)-P^{u}}{\theta}
$$

Moreover,

$$
V^{n}(\theta)=\frac{\theta\left[(v+\delta(1-G(x(\theta))) E(w \mid w \geq x(\theta))]+\delta G(x(\theta)) P^{u}-P^{n}\right.}{1-\delta G(x(\theta))-\delta^{2}(1-G(x(\theta)))}
$$

Proof: Consider the behavior of a consumer who owns a used car. If he chooses to sell a car of quality $x$, it must be that $\theta x+\delta V^{n}(\theta) \leq P^{u}+V^{n}(\theta)$ : the utility from holding on to a car of quality $x$ and buying a new car later must be no larger than the utility of selling the used car and buying the new car immediately. Then, for any $w<x, \theta w+\delta V^{n}(\theta)<P^{u}+V^{n}(\theta)$. Thus if he chooses to sell a car of quality $x$ he strictly prefers selling cars of lower quality. This proves that there is a cut-off $x(\theta)$ of the quality of the used such that the consumer sells all qualities below $x$ and keeps all qualities above $x$. Also, there can clearly be only one such cut-off for any $\theta$. Thus $x(\cdot)$ is a function. Moreover, this cut-off is defined by $\theta x(\theta)=(1-\delta) V^{n}(\theta)-P^{u}$. This says that the consumer is indifferent between keeping the used good of quality $x(\theta)$ and buying the new good again. Notice that we have allowed for the possibility that $x(\theta)$ is outside the support of $G(\cdot)$. If $x(\theta)>w^{h}$ the consumer sells the used car regardless of quality; if $x(\theta)<w_{l}$ the consumer keeps all quality realizations.

To obtain the expression for $V^{n}(\theta)$, notice that a consumer who owns nothing and buys a new car today will have discounted utility

$$
\left.V^{n}(\theta)=\theta v-P^{n}+\delta\left[(1-G(x(\theta)))\left(\theta E(w \mid w \geq x(\theta))+\delta V^{n}(\theta)\right)\right)+G(x(\theta))\left(P^{u}+V^{n}(\theta)\right)\right]
$$

This includes the current utility of enjoying the new car today minus its price, plus the future utility given by two different events. The first event involves keeping the good if the realization of $w$ is higher than $x(\theta)$, in which case the consumer enjoys the used and only in the following period buys a new car again. The complementary event is the one in which the consumer sells his used unit, for $P^{u}$, and immediately buys a new car again. Solving for $V^{n}(\theta)$ we get the desired expression.

\footnotetext{
${ }^{8} V^{n}(\theta)$ and $x(\theta)$ are also a function of $P^{n}$ and $P^{u}$ but, since this dependence is not exploited until much later, we shall suppress these arguments.
} 
We shall now prove that $x(\cdot)$ is increasing. Assume that $\theta<\theta^{\prime}$. By definition of $x(\cdot)$ : $\theta x(\theta)-P^{u}-(1-\delta) V^{n}(\theta)=0$ and $\theta^{\prime} x\left(\theta^{\prime}\right)-P^{u}-(1-\delta) \delta V^{n}\left(\theta^{\prime}\right)=0$. Combining the two equations we have:

$$
\theta^{\prime} x\left(\theta^{\prime}\right)-\theta x(\theta)=(1-\delta)\left(V^{n}\left(\theta^{\prime}\right)-V^{n}(\theta)\right)
$$

Suppose now by way of contradiction that $x(\theta) \geq x\left(\theta^{\prime}\right)$. Then we must have:

$$
\left(\theta^{\prime}-\theta\right) x(\theta) \geq(1-\delta)\left(V^{n}\left(\theta^{\prime}\right)-V^{n}(\theta)\right)
$$

But, since type $\theta^{\prime}$ could use the same rule as type $\theta$ (i.e., set $x\left(\theta^{\prime}\right)=x(\theta)$ ), by substituting below the expression for $V^{n}(\cdot)$ :

$$
\begin{gathered}
(1-\delta)\left(V^{n}\left(\theta^{\prime}\right)-V^{n}(\theta)\right) \geq \\
\geq \frac{(1-\delta)\left(\theta^{\prime}-\theta\right)[(v+\delta(1-G(x(\theta))) E(w \mid w \geq x(\theta))]}{\left.1-\delta G(x(\theta))-\delta^{2}(1-G(x(\theta)))\right)}>\left(\theta^{\prime}-\theta\right) x(\theta) .
\end{gathered}
$$

Where the last inequality holds because $(1-\delta)[(v+\delta(1-G(x(\theta))) E(w \mid w \geq x(\theta))]>[(1-$ $\delta) x(\theta)]+\left(\delta-\delta^{2}\right)(1-G(x(\theta))) x(\theta)$ since $v>x(\theta)$ and $E(w \mid w \geq x(\theta)) \geq x(\theta)$. This is in contradiction with Equation 6. Thus $x\left(\theta^{\prime}\right)>x(\theta)$.

The continuity of $x(\cdot)$ is obvious given the relationship between $x(\cdot)$ and $V^{n}(\cdot)$ and the fact that $V^{n}(\cdot)$ is continuous. ${ }^{9}$

Remarks: (i) Since $x(\cdot)$ is increasing higher types are more likely to trade in the used car market. It is easy to explain the expression for $x(\theta)$ : we must have that a consumer must be indifferent between keeping a car of quality $x(\theta)$ until next period (thereby postponing enjoyment of the value of the new) or selling it at price $P^{u}$ and immediately obtaining the value of the new.

(ii) In equilibrium it will turn out that $x(\theta)>w_{l}$ for all new car buyers.

We now want to consider how optimal behavior determines the classification of consumers in different categories as either (1) non-buyers, (2) buyers of used, or (3) buyers of new. Recall that buyers of new cars do not necessarily buy every period, they may choose to keep their used car if it is a high quality one. However, it turns out that a consumer who buys a new car at any date will never buy a used car. Thus it is meaningful to classify such a consumer as a new car buyer.

\footnotetext{
${ }^{9}$ Observe that the continuity of $V^{n}(\theta)$ is obvious since if $\theta$ is very close to $\theta^{\prime}$ the discounted utilities of the two types must be very close since each could imitate the behavior of the other and get almost the same utility.
} 
Intuition suggests that we should be able to partition the set of types in three intervals with the types in the lowest interval not buying anything, the types in the intermediate interval buying used cars and the types in the highest interval buying new cars. Moreover, we should be able to determine these types exactly from their utility of purchasing new or used.

Thus the lowest type who buys used (call him, $\theta^{u}$ ) should be the one who gets zero utility from purchasing used (i.e., $V^{u}\left(\theta^{u}\right)=0$ ) and the lowest type who buys new (call him $\theta^{n}$ ) should be the one who is indifferent between buying new and buying used (i.e., $V^{n}\left(\theta^{n}\right)=V^{u}\left(\theta^{n}\right)$ ).

This intuition is correct about equilibrium. However, we have to characterize consumer behavior for any $\left(w^{u}, P^{n}, P^{u}\right)$ and we must consider other cases that involve corner solutions.

Definition 2 Define $\theta^{n}=\inf \left\{\theta \in\left[\theta^{l}, \theta^{h}\right]: V^{n}(\theta) \geq V^{u}(\theta)\right\}$ and $\theta^{u}=\inf \left\{\theta \in\left[\theta^{l}, \theta^{n}\right]\right.$ : $\left.V^{u}(\theta) \geq 0\right\}$.

It is easy to see that the definition of $\theta^{u}$ and $\theta^{n}$ implies three cases depending on whether $\theta_{i}$ is interior or at two possible corners: $\theta^{u}$ is either (A) the solution of $V^{u}(\theta)=0$, (B) $\theta^{l}$ if $V^{u}\left(\theta^{l}\right)>0$, or (C) $\theta^{n}$ if $V^{u}(\theta)<0 \forall \theta$. $\theta^{n}$ is either (1) the solution of $V^{n}(\theta)=V^{u}(\theta)$, (2) $\theta^{l}$ if $V^{n}(\theta)>V^{u}(\theta) \forall \theta$, or (3) $\theta^{h}$ if $V^{n}(\theta)<V^{u}(\theta) \forall \theta$.

Lemma 4 For any $\left(w^{u}, P^{n}, P^{u}\right)$ consumer optimization determines a partition of types into three intervals: if $\theta \in\left[\theta^{l}, \theta^{u}\right]$ a consumer of type $\theta$ never buys a car, if $\theta \in\left(\theta^{u}, \theta^{n}\right]$ a consumer of type $\theta$ buys a used car every period; if $\theta \in\left[\theta^{n}, \theta^{h}\right]$ a consumer of type $\theta$ buys a new car every time he buys a car. Where $\theta^{u}$ and $\theta^{n}$ are defined in Definition 2.

Proof: Observe that $V^{u}(\theta)$ and $V^{n}(\theta)-V^{u}(\theta)$ are increasing. Thus, if a type $\theta$ prefers buying a new car to buying a used car, so do all the types higher than $\theta$. Analogously, if a type $\theta$ prefers buying a used car to buying nothing, so do all the ones above $\theta$.

Remarks:

(i) If $V^{n}(\theta) \geq V^{u}(\theta)$ at any date, $V^{n}(\theta) \geq V^{u}(\theta)$ at all subsequent dates. Thus, if $\theta \in\left[\theta^{n}, \theta^{h}\right]$ a consumer of type $\theta$ will never purchase a used car.

(ii) In equilibrium we will have that $\theta^{u}=\theta_{2 y}$ and $\theta^{n} \in\left(\theta_{2 y}, \theta_{y}\right)$. The first will be a consequence of market clearing (since there are exactly $2 y$ cars available at any given date). The second will arise from equilibrium trading behavior. Thus in equilibrium, we will have $\theta^{h}>\theta^{n}>\theta^{u}>\theta^{l}$, and none of the intervals described in the proposition will be empty. However, for out of equilibrium prices, we may very well have that some of these intervals are empty. For example, if the price of the new cars is very close to the price of used cars 
nobody will want to buy used cars so that $\theta^{u}=\theta^{n}$ would obtain. Alternatively, if the price of cars is too high, nobody will buy any cars and $\theta^{u}=\theta^{h}$.

\subsection{Equilibrium}

In order to go any further in our analysis we need to find out how keeping behavior by new car buyers affects the average quality of traded used cars $w^{A}$.

The determination of $w^{A}$ is complicated by the need to account for the relative frequency with which different types of consumers are in the market: different consumers have possibly different $x(\theta)$ 's so they may show up with different frequencies on the market. For example, if a consumer of type $\theta \geq \theta^{n}$ always kept its used car he would show up on the new market only half as often as a consumer of type $\theta^{\prime}$ who always sold his used car.

Lemma 5 The mean quality traded in the used market is:

$$
w^{A}=\int_{\theta^{n}}^{\theta^{h}} E(w \mid w \leq x(\theta)) d H(\theta)
$$

Where

$$
H(\theta)=\frac{\int_{\theta^{n}} \theta \frac{G(x(s))}{[2-G(x(s))]} d F(s)}{\int_{\theta^{n}}^{\theta^{h}} \frac{G(x(s))}{[2-G(x(s))]} d F(s)}
$$

denotes the distribution of consumer types who trade in the used car market at any given date.

Proof: The average quality traded by a type $\theta$ consumer is $E(w \mid w \leq x(\theta))$. By integrating over $\theta \geq \theta^{n}$ we obtain the average traded quality in the used market. The only thing that needs to be explained is the expression for $H(\theta)$, the distribution with respect to which we are integrating.

Denote by $\operatorname{pr}_{t}(\theta)$ the proportion of consumers of type $\theta$ who are present in the market for the new cars at date $t$. Observe that $(1-G(x(\theta))) p r_{t}(\theta)$ will decide to keep the car as their quality realization is higher than $x(\theta)$. We can solve for $\operatorname{pr}(\theta)$ by using the fact that, in a steady state, $1-p r_{t}(\theta)=(1-G(x(\theta))) p r_{t-1}(\theta)$, that is, the proportion of consumers of type $\theta \geq \theta^{n}$ who are not in the market for the new on any given date should equal the proportion of those getting high quality realizations out of the new buyers in the previous period. Thus we get:

$$
\operatorname{pr}(\theta)=\frac{1}{(2-G(x(\theta))} .
$$

Moreover, the proportion of consumers of type $\theta \geq \theta^{n}$ present in the used market as sellers is 


$$
G(x(\theta)) \operatorname{pr}(\theta)=\frac{G(x(\theta))}{(2-G(x(\theta))} .
$$

This explains the numerator of $H(\theta)$. The denominator is simply to normalize so that $H(\cdot)$ is a probability distribution.

The final component of the problem is the determination of the supply $\left(y_{s}^{u}\right)$ and demand $\left(y_{d}^{u}\right)$ of used cars and the demand of new cars $\left(y_{d}^{n}\right)$ for any $\left(w^{u}, P^{n}, P^{u}\right)$. Recall that the supply of new cars is exogenous and fixed at $y$.

Proposition 6 Supply of cars in the used market is:

$$
y_{s}^{u}=\int_{\theta^{n}}^{\theta^{h}} \frac{G(x(\theta))}{[2-G(x(\theta))]} d F(\theta)
$$

Demand in the used market is:

$$
y_{d}^{u}=F\left(\theta^{n}\right)-F\left(\theta^{u}\right)
$$

Demand in the market for new cars is:

$$
y_{d}^{n}=\int_{\theta^{n}}^{\theta^{h}} \frac{1}{[2-G(x(\theta))]} d F(\theta)
$$

Proof: The quantity of cars sold by consumers of type $\theta$ is $G(x(\theta))$. To obtain $y_{s}^{u}$ we need to integrate this over $\theta \geq \theta^{n}$ using the distribution that takes into consideration the accounting of the relative frequencies of consumer types obtained in equation 8 .

Since all consumers who buy used cars do so at every date, the demand for the used is simply the mass of consumers between $\theta^{u}$ and $\theta^{n}: F\left(\theta^{n}\right)-F\left(\theta^{u}\right)$.

Demand for the new is obtained by integrating over all types between $\theta^{u}$ and $\theta^{n}$ using the distribution that takes into consideration the accounting of the relative frequencies of consumer types derived in equation 8 .

Remark: Observe that $y_{d}^{n}>y_{s}^{u}$, i.e., the demand of new cars is larger than the supply of used cars. This is because new cars are demanded by the set of consumers who sell their used cars plus the set of consumers who kept their used cars the previous date. The first set is of measure $y_{s}^{u}$, the second set is of measure $\int_{\theta^{n}}^{\theta^{h}} \frac{1-G(x(\theta))}{[2-G(x(\theta))]} d F(\theta)$

Definition $3{ }^{10}$ An equilibrium is a triple $\left(w^{u}, P^{n}, P^{u}\right)$ such that:

$$
w^{u}=w^{A}\left(w^{u}, P^{n}, P^{u}\right), \quad y_{s}^{u}\left(w^{u}, P^{n}, P^{u}\right)=y_{d}^{u}\left(w^{u}, P^{n}, P^{u}\right), \quad y_{d}^{n}\left(w^{u}, P^{n}, P^{u}\right)=y
$$

\footnotetext{
${ }^{10}$ In the appendix we write down explicitly the way $w^{A}, y_{s}^{u}, y_{d}^{u}$, and $y_{d}^{n}$ depend on $\left(w^{u}, P^{n}, P^{u}\right)$.
} 
Thus, in equilibrium expectations about quality are correct, and supply equals demand in both the used car market and the new car market.

Theorem 7 An equilibrium exists.

The proof of this theorem involves first constructing a map such that existence of a fixed point of this map implies the existence of an equilibrium, and then showing that this map has a fixed point. The proof is presented in the appendix.

\subsection{Trade}

The next proposition shows that in the used car market there is always some trade and that the volume of trade is always lower than 100\%: some cars change hands in the used market but some consumers keep used cars of high quality. The fact that the used market never shuts down is in contrast with Akerlof style models. Section 4.5 shows that the volume of trade is quite high for reasonable parameters.

Theorem 8 In equilibrium the volume of trade is always less than 100\% but it is always positive: the used market never shuts down.

Proof: We know that in equilibrium we must have $V^{n}\left(\theta^{n}\right)=V^{u}\left(\theta^{n}\right)$, and $V^{u}\left(\theta_{2 y}\right)=0$ which implies $P^{u}=\theta_{2 y} w^{u}$. Suppose by way of contradiction that the volume of trade is $100 \%$. Then, for markets to clear, we must have that $\theta^{n}=\theta_{y}$. Also, all new car buyers must sell all realizations of quality: $x(\theta) \geq w_{h} \forall \theta \geq \theta_{y}$. Thus,

$$
w^{A}=E(w), P^{u}=\theta_{2 y} E(w), V^{n}\left(\theta_{y}\right)=V^{u}\left(\theta_{y}\right)=E(w)\left(\theta_{y}-\theta_{2 y}\right)
$$

The first equality comes from the fact that none of the quality realizations are kept from the market. The second comes from the definition of $\theta^{u}$, the fact that in equilibrium $\theta^{u}=\theta_{2 y}$, and $w^{A}=E(w)$. The third equality comes from the definition of $\theta^{n}$ and the fact that $\theta^{n}=\theta_{y}$ if there is full trade. The last equality comes from substituting $P^{u}$ into $V^{u}\left(\theta_{y}\right)$.

For $x\left(\theta_{y}\right) \geq w_{h}$ to be optimal, by equation 4 , we must have $\theta_{y} w_{h} \leq(1-\delta) V^{n}\left(\theta_{y}\right)+P^{u}=$ $\theta_{y} E(w)$; where the equality is a consequence of equation 14. But this requires that $w_{h} \leq E(w)$ which is impossible since the distribution of quality $G(\cdot)$ is non-degenerate. Since by equation $\Lambda_{x}(\theta)$ is continuous, there is a positive measure of types clase to $\theta_{g}$ who also want to keep some high quality used cars. Thus the volume of trade must be less than one hundred percent.

Let us now show that there is a positive volume of trade. Notice first that in any equilibrium $P^{u} \geq \theta_{2 y} w_{l}$ since quality can be no lower than $w_{l}$. Suppose by way of contradiction that 
there is no trade. Then $\theta^{n}=\theta_{2 y}$ since, when there is no trade, the type who is indifferent between buying used and buying nothing must also be the type who is indifferent between buying new and buying used. Consequently, we must have $V^{n}\left(\theta_{2 y}\right)=V^{u}\left(\theta_{2 y}\right)=0$ which allows us to solve for prices.

$$
P^{n}=\theta_{2 y}(v+\delta E(w)), V^{n}(\theta)=\frac{\left(\theta-\theta_{2 y}\right)(v+\delta E(w))}{1-\delta^{2}}
$$

Moreover, every type who buys new must be willing to keep a used car of quality $w_{l}: \theta w_{l} \geq$ $(1-\delta) V^{n}(\theta)+P^{u}$. Substituting for $V^{n}(\theta)$ from equation 15 we get

$$
\theta w_{l} \geq \frac{\left(\theta-\theta_{2 y}\right)(v+\delta E(w))}{(1+\delta)}+P^{u} \geq \frac{\left.\left(\theta-\theta_{2 y}\right)\right)(v+\delta E(w))}{(1+\delta)}+\theta_{2 y} w_{l}
$$

where the last inequality is a consequence of the fact that $P^{u} \geq \theta_{2 y} w_{l}$. Thus,

$$
\left(\theta-\theta_{2 y}\right) w_{l} \geq \frac{\left(\theta-\theta_{2 y}\right)(v+\delta E(w))}{(1+\delta)}>\left(\theta-\theta_{2 y}\right) E(w)
$$

Where the last inequality holds because $v>E(w)$. Since $E(w)>w_{l}$ we get a contradiction.

The intuition for the first part of the result is the following. For full trade to be an equilibrium outcome, even the lowest type who buys new must be willing to sell even the highest quality used car. However such a car is priced as if it were an average quality used car. Since the marginal type is indifferent in equilibrium between buying a new car and a used car he must strictly prefer keeping the highest quality used cars.

Let us now discuss the second part of the result. The logic is simple but powerful. In Akerlof style models the potential gains from trade come from the fact that the used car is in the wrong hands. Since ownership is endogenous in our model we cannot rely on such a force. Indeed, in our model the sellers of used cars are the new car buyers, high valuation consumers. If we froze our model at some period and looked at the used car market in isolation we would see that before the used market opens the used cars are owned by consumers with high valuation, and we would predict that they would not trade with lower valuation consumers who did not purchase new cars in the previous period. The gains from trade come from the interaction between the used market and the market for new goods, the fact that sellers of used cars are also new car buyers. They are the ones who have the highest opportunity cost of holding on to lemons because the difference in utility for them between having new cars and used cars is particularly high.

It is useful to consider the case in which the lowest quality of the used car is zero. If no trade is to be an equilibrium, all types who buy a new car must be willing to keep used 
cars of quality close to zero. However, this leads to a utility flow in that period that is close to zero, but consumers with high valuation for quality (types above $\theta^{n}$ ) get strictly positive continuation value from buying a new car. Therefore it cannot be optimal for them to keep such a low quality used car. This means that very low quality cars will certainly be sold by high valuation consumers.

This represents a real feature of markets for used cars: part of the reason people sell used cars is that they want to enjoy the higher flow of services that comes from owning a new car. This motive was absent in Akerlof's model, where the owner only has two choices, keeping the car or owning nothing. In our model the choice to keep a used car involves postponing the enjoyment of a new car.

The following result describes some further features of equilibrium that are a consequence of Theorem 8 .

Corollary 9 In equilibrium the lowest type to buy new cars is lower than when there is no quality uncertainty: $\theta_{2 y}<\theta^{n}<\theta_{y}$. The quality of traded used cars is adversely selected but always higher than the minimal possible quality: $w_{l}<w^{u}<E(w)$. Moreover, $x\left(\theta^{n}\right)=w^{u}$ and $x(\theta)<w_{h}$ for a positive measure of $\theta$ 's.

Proof: The fact that $\theta_{2 y}<\theta^{n}<\theta_{y}$ is a direct consequence of Theorem 8: since the volume of trade is strictly between zero and one hundred percent, in order for the market for new cars to clear it must be the case that some types below $\theta_{y}$ buy new cars; since some used cars are traded, it must be that there is positive mass between $\theta_{2 y}$ and $\theta^{n}$.

The fact that $w_{l}<w^{u}<E(w)$ is also a direct consequence of Theorem 8: some qualities above the minimal one are sold but not all new car buyers sell the highest quality cars.

By Theorem $8, x\left(\theta^{n}\right)<w_{h}$. Since $V^{n}\left(\theta^{n}\right)=V^{u}\left(\theta^{n}\right)$, by equation $4, \theta^{n} x\left(\theta^{n}\right)=(1-$ б) $V^{n}\left(\theta^{n}\right)+P^{u}=\theta^{n} w^{u}$. Therefore $x\left(\theta^{n}\right)=w^{u}$. The fact that $x(\theta)<w_{h}$ for a positive mass of $\theta$ 's follows from the continuity of $x(\cdot)$.

\subsection{The Effects of Adverse Selection on Prices}

We can now discuss how adverse selection affects prices. This will allow us to gain some insights into the impact of adverse selection on manufacturers' incentives.

Proposition 10 In equilibrium prices are as follows:

$$
P^{u}=\theta_{2 y} w^{u}, \quad P^{n}=\theta^{n}\left\{v+\delta E\left(w \mid w \geq w^{u}\right)\left(1-G\left(w^{u}\right)\right)-w^{u}\left(1+\delta\left(1-G\left(w^{u}\right)\right)\right\}+(1+\delta) \theta_{2 y} w^{u}\right.
$$


Proof: The expression for $P^{u}$ comes from the fact that in equilibrium $\theta^{u}=\theta_{2 y}$ and $V\left(\theta^{u}\right)=$ 0 . The expression for $P^{n}$ comes from setting $V^{n}\left(\theta^{n}\right)=V^{u}\left(\theta^{n}\right)$, substituting $P^{u}=\theta_{2 y} w^{u}$ and using the fact (from corollary 9) that $x\left(\theta^{n}\right)=w^{u}$.

In order to understand the effects of adverse selection on prices, it is useful to compare equilibrium prices under adverse selection to equilibrium prices when there is no quality uncertainty (section 3.1). This comparison is interesting because we saw in section 3.1 that we can interpret the case of no quality uncertainty as one where there is quality uncertainty but no adverse selection because nobody knows the realization of quality. The same allocation would arise if new car buyers learn the realization of quality but they are forced to trade regardless of the quality realization. This may happen because of taxes or because cars are leased and the option price for repurchase is set very high. The comparison is also a comparative statics exercise on the variance of the quality of cars, a variable that manufacturers have control over. For the purpose of this comparison we want cars to have the same characteristics except for the uncertainty; thus we shall assume that used cars have the same expected quality $E(w)$ in both cases. Recall that $P_{d}^{u}, P_{d}^{n}$ denote prices for the case of no quality uncertainty and, by Proposition 1 ,

$$
P_{d}^{u}=\theta_{2 y} E(w), P_{d}^{n}=\theta_{y} v-\left(\theta_{y}-\theta_{2 y}\right) E(w)+\delta P_{d}^{u}
$$

The effect of adverse selection on the price of used cars is unambiguous: by Theorem 8 $w^{u}<E(w)$ thus the price of used cars in the presence of adverse selection is lower than when there is no quality uncertainty.

The effect of adverse selection on the price of new cars is more complex but it is possible to understand the forces at work. We can rewrite the price when there is adverse selection as follows:

$$
P^{n}=\theta^{n}\left[v+\delta\left(1-G\left(w^{u}\right)\right)\left(E\left(w \mid w \geq w^{u}\right)-w^{u}\right)\right]-\left(\theta^{n}-\theta_{2 y}\right) w^{u}+\delta P^{u}
$$

Thus, there are exactly four causes for the difference between $P^{n}$ and $P_{d}^{n}:$ 1) Shift of the marginal consumer. The marginal consumer $\theta^{n}$ is lower under adverse selection: $\theta^{n}<\theta_{y}$ by Corollary 9. 2) Option value effect. Under adverse selection, there is an option value in buying a new good that may turn out to be of high used quality and therefore worth keeping. This effect is captured by the term $\delta\left(1-G\left(w^{u}\right)\right)\left(E\left(w \mid w \geq w^{u}\right)-w^{u}\right)$ which is positive and is absent in the case of degenerate quality. 3) Substitution effect. This is captured by the term $-\left(\theta^{n}-\theta_{2 y}\right) w^{u}$. Since $w^{u}<E(w)$, the reduction in the expected used quality makes the used good a worse alternative for buyers of the new. The substitution effect raises the price 
of the new. (4) Resale value effect. Since $P^{u}<P_{d}^{u}$, the presence of adverse selection reduces the resale value of the new car hence the willingness to pay of new car buyers.

All these effects are also present when we compare markets with more or less dispersed distributions of quality. Effects (1) and (4) push down the price of the new whereas effects (2) and (3) push it up. We will see in section 4.5 examples in which the price of new cars is higher under adverse selection and other examples where the price is lower. The fact that prices of new cars can be higher under adverse selection is interesting because it means that adverse selection need not hurt manufacturers. By choosing how rigorous to make their quality control process, manufacturers can control the reliability of their products. A brand that is very reliable is not subject to adverse selection. If prices are higher under adverse selection there is no incentive to produce reliable cars.

\subsection{The Uniform case}

The following is a numerical analysis of the model under the assumption that the distribution of tastes and quality, $(F(\cdot)$ and $G(\cdot))$ are both uniform. We assume the support of the distribution of $\theta$ is $\left[0, \theta^{h}\right]$, while the support of the distribution of $w$ is $[1-s, 1+s]$. The variable $s$ captures the extent of quality uncertainty in the used good market and therefore the potential severity of adverse selection. We computed the equilibrium for different values of $s$, as well as different values of the other parameters, $v, \delta$ and different output levels $y$.

Assuming $G$ is uniform is convenient since it leads to an analytic solution for $x(\theta)$. By plugging the uniform distribution of quality in the expressions that define $V^{n}$ and $x(\cdot)$ in Proposition 3 we get:

$$
x(\theta)=\left(\frac{2 s}{\delta}+s+1\right)-\frac{2}{\theta \delta} s \sqrt{\left(\frac{\theta}{s}\left(\theta s+\theta \delta s+\theta \delta-\delta \theta v+\delta P^{n}-P^{u} \delta-P^{u} \delta^{2}\right)\right)}
$$

The model could be solved for any distribution function, but the solution would involve numerically approximating $x(\theta)$ in a grid of values of $\theta$. The search would then involve three parameters $\left(w^{u}, P^{n}, P^{u}\right)$ plus a whole grid of values of $x(\theta)$. The enormous computational simplicity gained by using the uniform distribution is clear; it avoids having to nest one fixed point into another (nesting the one that generates $x(\theta)$ into the one that determines the equilibrium prices and quantities).

We first focus on the effects of a change in $s$, the spread of the distribution of quality. This will show how the extent of quality uncertainty affects equilibrium variables in the presence of adverse selection. The other parameters of the model are held constant at $\delta=0.8, v=2$, $\theta^{h}=1$, and $y=0.3$. 
Figure 1a shows how $P^{n}$ varies with $s$. It first declines and then increases, showing that the four effects discussed in Section 4.4 that relate a change in the variance of $w$ to $P^{n}$ have different magnitudes in different regions of $s$. While in this example $P^{n}$ is maximized at $s=0$. This is not always the case (we discuss this below).

Figure $1 \mathrm{~b}$ shows the price of the used as a function of $s$. This price declines monotonically and drops by as much as $50 \%$ as a consequence of the increased uncertainty. Clearly this decline is a consequence of adverse selection since the price of a used car would be independent of $s$ if all cars were traded in the used market and buyers did not need to take into account the fact that the higher quality cars disappear from the market (recall that consumers are risk neutral).

Figure 1c describes the volume of trade in the used market. This drops from full trade when there is no uncertainty about quality (as predicted by the first benchmark case in Section 3 ) to only $40 \%$ when uncertainty is high.

We solved the equilibrium for a variety of values of $v, \delta$, and $y$. The effect of $v$ and $\delta$, is quite predictable. Although they do not affect the qualitative features of the equilibrium, increases in $v$ as well as declines in $\delta$ reduce the importance of the used good relative the new one, weakening the effect of $s$ on equilibrium quantities. Figure $1 \mathrm{~d}$ shows how the volume of trade is affected by $y$. As expected for small $s$ volume of trade is $100 \%$, but for large $s$ volume of trade (VOT) increases in $y$. For a lower $y$ the preferences of the consumers active in the market are less diverse. This is because there is a smaller distance between $\theta^{h}$ and $\theta_{2 y}$. Clearly the more homogeneous are preferences the less scope there is for exploiting gains from trade; hence VOT is lower. For a large $s$ and a small $y$ VOT is only $10 \%$, while for large $y$ VOT is substantial even when the uncertainty about the quality of the used good is maximal (i.e., the worst cars are useless while the best ones are as good as new). To confirm the impact of preference heterogeneity on VOT we present in Figure 2a the equilibrium VOT when we perform a mean preserving spread to the distribution of $\theta$ (for $y=0.3$ ). The distribution of $\theta$ is assumed uniform $[.5-s p, .5+s p]$. We present the cases $s p=.5,1.5$ and 2.5. VOT increases in $s p$ for every $s$. The conclusion is that a substantial VOT is present as long as preferences are heterogenous enough, regardless of the severity of the information asymmetry. Figure $2 \mathrm{~b}$ replicates the case of figure 1a for a larger $y$. We see that for a large $y$ the price of the new good is maximized for a high level of $s$.

\subsection{Welfare}

Let us first look at two examples to understand the welfare consequences of adverse selection in our model. The first example highlights one dimension of inefficiency of the equilibrium 
allocation in a world with adverse selection. It also suggests a very simple policy that would lead to a Pareto improvement. In the second example the equilibrium allocation is first best efficient despite the fact that the volume of trade in the used market is less than $100 \%$. A policy that would increase the volume of trade in the used market would be inefficient. Observe that in the examples, because there are only two types, ex-post efficiency requires maximizing the average quality consumed by the high types.

\section{Example 1}

There are two types: $\theta_{L}, \theta_{H}$. The mass of the high types, $\mu\left(\theta_{H}\right)$ is such that $\mu\left(\theta_{H}\right)<y<$ $1 / 2$. The role of the assumption that $\mu\left(\theta_{H}\right)<y$ will become clear in the next example. The role assumption that $y<1 / 2$ is just as in the rest of the paper to guarantee that there is some scarcity of used cars so that no the used car is scrapped. Suppose also that $w_{h}=v$. This is not essential for the substance of the example but simplifies the discussion. Therefore, since there are enough new cars to let the high types consume a new car every period, the ex-post efficient outcome involves all high types consuming new cars every period. Thus high types should never keep any used car. However, in equilibrium the high types will certainly choose to keep some of the highest quality used cars. This is easy to show: given that $w_{h}=v$ and that, in equilibrium, $P^{u}<P^{n}$, all high types want to keep a positive measure of realizations of used cars.

In this example a very simple policy would increase welfare: either a subsidy to trade or a tax on keeping would lead to improvements. Ex post efficiency can be obtained by making the high types never want to keep the used car. There is clearly a subsidy or tax high enough to implement this. ${ }^{11}$

\section{Example 2}

In the second example we find that there are cases where the self selection of consumers into new car buyers or used car buyers can lead to efficient allocations. Since we need to compute the equilibrium more explicitly here we shall assume numerical values for the parameters. This example also involves two types but, in contrast with example 1 , there is not enough output for high types to consume new cars every period. Assume that $\theta_{H}=$ $1, \theta_{L}=1 / 2, y=1 / 3, \mu\left(\theta_{H}\right)=\mu\left(\theta_{L}\right)=1 / 2, G(w)$ is uniform on $[1-s, 1+s], v=2, \delta=.8$. It is easy to show that the following is the unique equilibrium: $x\left(\theta_{H}\right)=1, P^{n}=1.95-.25 s$; only high types buy new and no high types buy used. Thus high types keep the upper half of the realizations of quality, just enough so that the high types exactly exhaust all new cars: no new cars are left for the low types. This equilibrium allocation is ex-post efficient:

\footnotetext{
${ }^{11}$ This can be done with budget balance since, if the tax on keeping is high enough, nobody keeps and nobody pays the tax.
} 
there is no way to re-allocate quality between high types and low types to improve welfare. It is interesting to compute the difference between welfare in the equilibrium under adverse selection to what welfare would be if, through a tax or subsidy scheme, we implemented a full trade allocation where all cars are sold regardless of the quality realization. Letting $W^{A S}$ and $W^{F T}$ denote welfare (consumer surplus plus producer surplus) under adverse selection and under full trade respectively, we have: $W^{A S}-W^{F T}=s / 24$. Thus increasing trade would be inefficient in this case. The reason is simple: if the high types keep fewer realizations of quality (i.e., they increase their volume of trade), some high types must buy used cars. Thus, after such a subsidy, low types consume higher quality on average (average quality of traded used cars goes up), and high types consume lower quality on average, a misallocation of quality.

It may seem that there is a knife edge feature about the equilibrium but the example is robust to any small perturbation of the parameters except the number of types (see example 3). An analogous example can be made with types $\theta_{H}=1.5, \theta_{L}=1$, and $v=3$. In this case the equilibrium value of $P^{n}$ is: $P^{n}(s)=4.8-.6 s$. Thus we have an example with the same preference parameters as in the Akerlof world where the equilibrium is socially optimal.

To summarize, the equilibrium allocation under adverse selection can be ex-post efficient (as shown in example 2) but may not even be constrained efficient (example 1). Subsidizing trade may lead to welfare losses.

By comparing the features of the market allocation under adverse selection with the expost efficient allocation described in Proposition 2, we can make an additional observation on the distortions caused by asymmetric information. The allocation under adverse selection involves all types who buy used cars consuming the same average quality. This is inefficient when there is more than one type consuming used cars because, as we saw in section 3.2 , ex-post efficiency requires that higher types consume higher quality.

\section{Two Brands}

We now want to extend the model to an environment with several brands of cars. The purpose of the exercise is to understand how differences in the severity of adverse selection across brands generate observable differences in market outcomes. We find that despite having the same mean qualities, brands with different reliability have different price profiles. Moreover, the market gets segmented with reliable brands appealing to consumers who want to trade often. Finally, the predictions of the model provide a direct test of the presence of adverse selection based on market observables: prices and volume of trade. 
There are two brands: Honda and Ford. There is a flow of output of $y_{H}$ Hondas and $y_{F}$ Fords. Let $y=y_{H}+y_{F}$. In order to isolate the effects of adverse selection we shall assume that both brands have the same quality of new cars $v$ and the same average value of used cars $E(w)$. However, as suggested by Consumer Reports ratings, Hondas are more reliable. We shall represent this by making the assumption that the distribution quality of used Hondas is degenerate at $E(w)$, whereas the quality of used Fords is distributed $G(\cdot)$ with mean $E(w)$. Therefore the only difference across the two brands is that used Fords have random quality. The expected flow of services to a consumer who plans to keep the car two periods would be the same for both brands. Thus any difference in prices and volume of trade across the two brands are due to adverse selection.

It is easy to characterize equilibrium in this environment given the analysis of the previous section. The discussion in this section will be less formal. Existence of equilibrium follows easily from Theorem 7 . It is also easy to show that we can partition the set of types into three intervals with the lowest types not buying any car, types in the intermediate interval buying used cars and the highest types buying new cars. Moreover, just as in section 3.1, in equilibrium, all Hondas are traded in the used market; the volume of trade for Hondas is $100 \%$. Analogously, just as in Theorem 8 , the volume of trade for Fords is positive but less than $100 \%$. Thus, if we denote by $w_{H}^{A}, w_{F}^{A}$ the equilibrium quality of traded Hondas and Fords, we have that $w_{H}^{A}=E(w)>w_{F}^{A}>w_{l}$, meaning that traded used Hondas are of higher quality. This has the interesting implication that we can partition the set of types who buy used cars into a set of lower types who buy used Fords and a set of higher types who buy used Hondas. The reason for this is clear: because the quality of used Hondas is higher, just as in section 3.2 , consumers of used cars will self-select so that higher types will buy used Hondas. This allows us to obtain the prices of both brands of used cars as follows. The lowest type who buys a used Ford is type $\theta_{2 y}$. Let $\theta^{u H}$ be the lowest type who buys a used Honda, then:

$$
P_{F}^{u}=\theta_{2 y} w_{F}^{A}, P_{H}^{u}=\theta^{u H}\left(w_{H}^{A}-w_{F}^{A}\right)+\theta_{2 y} w_{F}^{A}
$$

The first price is obtained by setting the utility of type $\theta_{2 y}$ equal to zero. The second price is obtained from the observation that type $\theta^{u H}$ must be indifferent between the two brands of used cars.

Let us turn to a discussion of the new car market. The rental price of Hondas $\left(P_{H}^{n}-\delta P_{H}^{n}\right)$ must be lower than the rental price of Fords $\left(P_{F}^{n}-\delta P_{F}^{u}\right)$ otherwise nobody would be willing to buy Hondas. In order to see this, consider the type who is indifferent between a buying a new Honda and a new Ford. Denote this type by $\hat{\theta}$. Since a consumer buying a new Ford also gets the option of keeping the high realizations of quality of the used, it must be that the 
rental price of Hondas - that do not have this option - is cheaper, i.e. $P_{H}^{n}-\delta P_{H}^{u} \leq P_{F}^{n}-\delta P_{F}^{u}$. Formally, notice that

$$
V_{H}^{n}(\hat{\theta})=\frac{\hat{\theta} v-P_{H}^{n}+\delta P_{H}^{u}}{1-\delta}
$$

Since $V_{H}^{n}(\hat{\theta})=V_{F}^{n}(\hat{\theta})$, substituting $V_{F}^{n}(\theta)$ and solving we get $P_{H}^{n}-\delta P_{H}^{u}=\hat{\theta} v-(1-\delta) V_{F}^{n}(\hat{\theta})$. But

$$
V_{F}^{n}(\hat{\theta}) \geq \frac{\hat{\theta} v-P_{F}^{n}+\delta P_{F}^{u}}{1-\delta}
$$

since selling all realizations of quality is feasible (although keeping high realizations of quality may be a better choice). Plugging $V_{F}^{n}(\hat{\theta})$ into the previous equality we get $P_{H}^{n}-\delta P_{H}^{u} \leq$ $P_{F}^{n}-\delta P_{F}^{u}$. We thus have

Proposition 11 The price decline is steeper and the volume of trade is lower for the unreliable cars.

It is seemingly unintuitive that a consumer would be willing to pay a higher rental price for a less reliable car (when they have the same mean qualities). Why wouldn't all consumers buy the more reliable car, after all it gives the same first period quality at a lower cost. The intuition behind the result is that Fords appeal to a segment of consumers who, at equilibrium prices, are not willing to pay enough to consume quality $v$ every period. By buying new Fords, and keeping them some of the time, they consume an average quality lower than $v$, which in turn is cheaper for them. They end up keeping high draws at the price $P_{F}^{u}$. That is why the seemingly more expensive Fords is the alternative preferred by a specific segment of the market.

We now want to show that we can also partition the set of types who buy new cars into a set of lower types who buy the unreliable brand and a set of higher types who buy the reliable brand. In equilibrium some of the types who buy a new Ford will choose to keep the high realizations of quality of the used (recall that the volume of trade of Fords is never 100\%). In contrast none of the types who buy new Hondas keep them (the volume of trade for Hondas is $100 \%$ ). Those consumers who buy Fords and sometimes keep are therefore consuming an average quality over two periods which is lower than $v$, the quality consumed by consumers of new Hondas. Thus, once again, lower types will be the ones who self select into buying Fords. Observe that the highest average quality that can be consumed over two periods is $v$. This can be done with either brand. However, by Proposition 11 the rental price of Hondas is lower so consumers who plan to sell all the time spend less if they purchase Hondas. We thus obtain the following: 
Proposition 12 The presence of two brands and adverse selection segments consumers into the following intervals:

\begin{tabular}{l|c|c|c|}
\hline Used Ford & Used Honda & New Ford & New Honda \\
\hline$\theta_{2 y} \theta^{u a}$ & $\theta^{u b}$ & $\theta^{n a}$ & $\theta^{h}$
\end{tabular}

We saw in the introduction that the Ford Taurus has steeper price declines than the Honda Accord. The same is true if we compare the Honda Civic with the Ford Escort. This is consistent with proposition 11 .

\subsection{The Uniform Case with Two Brands}

We now discuss an example that is similar to the one discussed in Section 4.5 to get a better idea of equilibrium with two brands. Figure $3 \mathrm{a}$ and $3 \mathrm{~b}$ present the price of new and used goods as a function of the variance of the quality of the used Fords. The parameters are the same as in the one brand case presented in Section 4.5: $v=2, \delta=.8$ and $y^{F}+y^{H}=.3$. Just as in the case of one brand, $P_{F}^{U}$ decreases in $s . P_{H}^{u}$ increases in $s$. This is interesting because a change in $s$ (the variance of quality of used Fords) does not alter the characteristics of Hondas. This is due to the substitution effect; Fords becomes a worse substitute as $s$ increases, making the marginal buyer willing to pay more for Hondas.

$P_{F}^{n}$ first declines and then increases in $s$. In comparison to the one brand case, $P_{F}^{n}$ is above $P^{n}$, (figure 1a). The main difference between these cases is that the used good of one brand is no longer a substitute for the new good of the same brand. Now the substitute of a new Ford is a used Honda. Finally, Figure 3c presents rental prices as a function of $s$. Interestingly, Fords become substantially more expensive to rent than Hondas as $s$ increases. This has to do with Proposition 11. Buying Fords provides both the value of services $v$ and an option of keeping the high realizations.

\subsection{Depreciation and the Volume of Trade}

The steeper price decline of a Ford relative to a Honda can also be explained by faster quality deterioration. We shall now show that these two alternative explanations have opposite implications on the volume of trade. This means that volume of trade data can be used to understand the relative importance of the two alternative explanations. Suppose that the quality of a new Ford is $v_{F}$, the quality of a used Ford is $w_{F}$, the quality of a new Honda is $v_{H}$, and the quality of a used Honda is $w_{H}$. In order to match the observed price paths, we assume that $v_{F} \geq v_{H}$ and $w_{F}<w_{H}$. Since there is no asymmetric information, just as in section 3.1 , in the absence of transaction costs there would be $100 \%$ trade in both Hondas 
and Fords. We assume that if a used car changes hand a transaction cost $T$ is incurred. If the used car is kept by the owner no transaction cost is incurred. Without loss of generality we assume that the transaction cost is paid by the used car buyer.

Since the used Ford is of lower quality, types who buy it will be lower than those wo buy the used Honda. Since the lowest type who buys a used Ford is type $\theta_{2 y}, P_{F}^{n u}=\theta_{2 y} w_{F}-T$. As long as there is some trade in used Hondas, which occurs as long as transaction costs are not too large, the price of a used Honda must make the lowest type to buy it (call him $\theta^{u H}$ ) indifferent between buying it and buying a used Ford. Thus, $P_{H}^{u}=\theta^{u H}\left(w_{H}-w_{F}\right)+\theta_{2 y} w_{F}-T$. Analogously, since $v_{F} \geq v_{H}$, we can partition the set of consumers who buy new cars at every date into a set of lower types who buy Hondas and a set of higher types who buy Fords. Let $\theta^{F}$ be the consumer type who is indifferent between a Honda and a Ford. Then, $\theta^{F} v_{F}-P_{F}^{n}+\delta P_{F}^{u}=\theta^{F} v_{H}-P_{H}^{n}+\delta P_{H}^{u}$, which implies $P_{F}^{n}-\delta P_{F}^{u} \geq P_{H}^{n}-\delta P_{H}^{u}$; the rental price of a Ford is higher, or the price decline is larger. If a consumer of type $\theta \in\left(\theta^{u H}, \theta^{F}\right)$ buys a new Ford every two periods and keeps the used, his utility would be:

$$
\begin{aligned}
& \frac{\theta\left(v_{F}+\delta w_{F}\right)-P_{F}^{n}}{1-\delta^{2}}=\frac{\theta\left(v_{F}+\delta w_{F}\right)-P_{H}^{n}+\delta\left(P_{H}^{u}-P_{F}^{u}\right)+\theta^{F}\left(v_{F}-v_{H}\right)}{1-\delta^{2}}= \\
& \frac{\theta\left(v_{F}+\delta w_{F}\right)-P_{H}^{n}+\theta^{u H}\left(w_{H}-w_{F}\right)+\theta^{F}\left(v_{F}-v_{H}\right)}{1-\delta^{2}}<\frac{\theta\left(v_{H}+\delta w_{H}\right)-P_{H}^{n}}{1-\delta^{2}}
\end{aligned}
$$

The first equality comes from the indifference condition for $\theta^{F}$. The second equality comes from substituting the prices of used cars. The last expression is the utility from buying a new Honda and keeping. We have shown that, for all types who keep, the utility from buying a new Honda and keeping is higher than that of buying a new Ford and keeping. Therefore no consumer will keep the used Ford. Since some consumers must keep when there are transaction costs, the volume of trade in Hondas will be less than $100 \%$. We can then conclude that the volume of trade of the Ford is higher than the volume of trade of the Honda. The intuition for this result is that the higher quality of a used Honda leads consumers who plan to keep to self-select into buying new Hondas instead of Fords.

We can also determine how the market is segmented in this case. We saw that buyers of used Hondas have higher valuations than buyers of used Fords. Since buyers of new Fords do not keep, they consume higher quality than buyers of new Hondas. Consequently, they must be consumers with higher valuations. Thus, the presence of two brands with different rates of depreciation segments consumers into the following intervals:

\begin{tabular}{c|c|c|c|}
\hline Used Ford & Used Honda & New Honda & New Escort \\
\hline$\theta_{2 y}$ & $\theta^{C H}$ & $\theta^{F}$ & $\theta^{h}$
\end{tabular}


Observe the difference between this and the intervals generated in the case of adverse selection. The buyers of new Hondas are now lower types than buyers of new Fords.

We have shown that two alternative explanations for the observed differences in the time profile of prices have an opposite implication on the volume of trade in the used market. If the reason for observed differences in the time path of prices is adverse selection, Fords should have a lower volume of trade than Hondas. If the reason is that the quality of Fords is initially higher but deteriorates faster, then Fords should have a larger volume of trade.

\section{Concluding Remarks and Related Literature}

The literature on adverse selection is extensive. Here we shall briefly discuss the contributions that are most directly related to our paper. Akerlof (1970) was the first to develop a model of adverse selection. He found the used car market to be the most direct application of the model. His paper mostly discusses the example outlined in the introduction. Wilson (1980) extends Akerlof's model by allowing for many potential types of buyers while maintaining the assumptions of a single type of seller and exogenous ownership of cars. He also explores alternatives to Walrasian markets, such as buyers making offers to sellers, and shows that these may lead to equilibria that are not characterized by a single price. Kim (1985) presents a model where the source of asymmetric information is that used car buyers do not know how well a car has been maintained. The quality of a car is assumed to be a deterministic function of the amount of maintenance. The main result of the paper is that traded used cars may be of higher quality than cars that are kept by the owners.

We presented a model of adverse selection that incorporates the market for new goods. We showed that the presence of the new good as a superior substitute for the used good endogenously determines the identity of used car sellers. Moreover, the endogenous ownership leads to a dilution of the effects of adverse selection. The used good market never shuts down and, for sensible parameters, the volume of trade is substantial even in cases of extreme informational asymmetries. Modelling the interaction between used and new markets enabled us to study manufacturers' incentives to supply reliable goods. We found that in a single brand case the manufacturers may not be harmed by adverse selection. In a multi-brand market, low reliability can be used by manufacturers to segment the market.

Results in Section 5 provide a sharp test for adverse selection that relies only on observable data on price and quantity profiles over time across brands of cars. According to the model we have evidence of adverse selection if the car that has a steeper price decline also has the lower volume of trade. If instead it has a larger volume of trade, then the steeper price decline 
may be due to faster physical depreciation.

\section{Appendix}

\subsection{Proof of Proposition 2}

Proof: The fact that all used cars are traded in the used market is analogous to the proof of proposition 1. In this case, the value to a consumer of type $\theta$ who is a used car buyer is

$$
V^{u}(\theta)=\frac{\vartheta(w) w-P(w)}{1-\delta}
$$

and the value to a new car buyer is

$$
V^{n}(\theta)=\frac{\theta v-P_{o}^{n}+\delta E(P(w))}{1-\delta}
$$

where $E(P(w))$ is the expected value of the price of a used car.

The expression $F(\vartheta(w))-F\left(\theta_{2 y}\right)=y G(w) \forall w \in\left[w_{l}, w_{h}\right]$ represents market clearing for an increasing $\vartheta(\cdot)$.

To prove that $\vartheta(\cdot)$ is increasing observe first that $P(\cdot)$ must be strictly increasing. Otherwise, if $w>w^{\prime}$ and $P(w) \leq P\left(w^{\prime}\right)$, nobody would want to consume cars of quality $w^{\prime}$.

Since trading is anonymous, a consumer of type $\vartheta\left(w^{\prime}\right)$ could choose to consume a car of quality $w$. For him not to prefer this we must have:

$$
\vartheta\left(w^{\prime}\right) w^{\prime}-P\left(w^{\prime}\right) \geq \vartheta\left(w^{\prime}\right) w-P(w) \Leftrightarrow \vartheta\left(w^{\prime}\right)\left(w^{\prime}-w\right) \geq P\left(w^{\prime}\right)-P(w)
$$

Analogously,

$$
\vartheta(w)\left(w-w^{\prime}\right) \geq P(w)-P\left(w^{\prime}\right)
$$

Thus,

$$
\vartheta(w)\left(w^{\prime}-w\right) \leq P\left(w^{\prime}\right)-P(w) \leq \vartheta\left(w^{\prime}\right)\left(w^{\prime}-w\right)
$$

Therefore, if $w<w^{\prime}, \vartheta(w)<\vartheta\left(w^{\prime}\right)$. We can also rewrite the previous inequalities for any $\mu>0$ as follows:

$$
\vartheta(w) \mu \leq P(w+\mu)-P(w) \leq \vartheta(w+\mu) \mu
$$

Since $\vartheta(w)$ is increasing in $w$, it is Riemann integrable. So:

$$
P(w)-P\left(w_{l}\right)=\int_{w_{l}}^{w} \vartheta(s) d s
$$

Since $P\left(w_{l}\right)=\theta_{2 y} w_{l}$ we obtain the desired expression. 
To compute $P_{o}^{n}$ observe that this price must make a consumer of type $\theta_{y}$ indifferent between buying new and buying a used car of quality $w_{h}$. Therefore: $\theta_{y} v-P_{o}^{n}+\delta E(P(w))=$ $\theta_{y} w_{h}-P\left(w_{h}\right)$ where $E(P(w))=\int_{w_{l}}^{w_{h}} P(w) d G(w)$.

\subsection{Proof of Theorem 7}

Proof: We need to prove that there exists a triple $\left(w^{u}, P^{n}, P^{u}\right)$ such that

$$
w^{u}=w^{A}\left(w^{u}, P^{n}, P^{u}\right), \quad y_{s}^{u}\left(w^{u}, P^{n}, P^{u}\right)=y_{d}^{u}\left(w^{u}, P^{n}, P^{u}\right), \quad y_{d}^{n}\left(w^{u}, P^{n}, P^{u}\right)=y
$$

Where,

$$
\begin{gathered}
y_{s}^{u}\left(w^{u}, P^{n}, P^{u}\right)=\int_{\theta^{n}\left(w^{u}, P^{n}, P^{u}\right)}^{\theta^{h}} \frac{G\left(x\left(\theta, w^{u}, P^{n}, P^{u}\right)\right)}{\left[2-G\left(x\left(\theta, w^{u}, P^{n}, P^{u}\right)\right)\right]} d F(\theta) \\
y_{d}^{u}\left(w^{u}, P^{n}, P^{u}\right)=F\left(\theta^{n}\left(w^{u}, P^{n}, P^{u}\right)\right)-F\left(\theta^{u}\left(w^{u}, P^{n}, P^{u}\right)\right) \\
y_{d}^{n}\left(w^{u}, P^{n}, P^{u}\right)=\int_{\theta^{n}\left(w^{u}, P^{n}, P^{u}\right)}^{\theta^{h}} \frac{1}{\left[2-G\left(x\left(\theta, w^{u}, P^{n}, P^{u}\right)\right)\right]} d F(\theta) \\
w^{A}=\int_{\theta^{n}\left(w^{u}, P^{n}, P^{u}\right)}^{\theta^{h}} E\left(w \mid w \leq x\left(\left(\theta, w^{u}, P^{n}, P^{u}\right)\right)\right) d H(\theta)
\end{gathered}
$$

It is easy to show that all of these functions are continuous.

Define

$$
e^{u}\left(w^{u}, P^{n}, P^{u}\right)=y_{s}^{u}\left(w^{u}, P^{n}, P^{u}\right)-y_{d}^{u}\left(w^{u}, P^{n}, P^{u}\right), e^{n}\left(w^{u}, P^{n}, P^{u}\right)=y-y_{d}^{n}\left(w^{u}, P^{n}, P^{u}\right)
$$

Define also

$$
\lambda^{u}\left(w^{u}, P^{n}, P^{u}\right)=1-\frac{a b s\left(e^{u}\left(w^{u}, P^{n}, P^{u}\right)\right)}{\max \left(y_{s}^{u}, y_{d}^{u}\right)}
$$

and

$$
\begin{gathered}
\lambda^{n}\left(w^{u}, P^{n}, P^{u}\right)=1-\frac{a b s\left(e^{n}\left(w^{u}, P^{n}, P^{u}\right)\right)}{\max \left(y, y_{d}^{n}\right)} \\
\phi^{u}\left(w^{u}, P^{n}, P^{u}\right)=\lambda^{u}\left(w^{u}, P^{n}, P^{u}\right) P^{u}+ \\
\left(1-\lambda^{u}\left(w^{u}, P^{n}, P^{u}\right)\right)\left(1\left[e^{u}\left(w^{u}, P^{n}, P^{u}\right) \leq 0\right] \theta_{2 y} w^{l}+1\left[e^{u}\left(w^{u}, P^{n}, P^{u}\right)>0\right] \theta_{2 y} E(w)\right)
\end{gathered}
$$




$$
\begin{gathered}
\phi^{n}\left(w^{u}, P^{n}, P^{u}\right)=\lambda^{n}\left(w^{u}, P^{n}, P^{u}\right) P^{u}+ \\
\left(1-\lambda^{n}\left(w^{u}, P^{n}, P^{u}\right)\right)\left(1\left[e^{n}\left(w^{u}, P^{n}, P^{u}\right) \leq 0\right] \theta_{2 y} v+1\left[e^{n}\left(w^{u}, P^{n}, P^{u}\right)>0\right] \theta_{y} 2 v\right) \\
\phi^{w}\left(w^{u}, P^{n}, P^{u}\right)=w^{A}\left(w^{u}, P^{n}, P^{u}\right)
\end{gathered}
$$

Finally, let $\Phi: K \rightarrow K=\left[\phi^{w}, \phi^{n}, \phi^{u}\right]$. Where $K=\left[w^{l}, E(w)\right] \times\left[\theta_{2 y} v, \theta_{y} 2 v\right] \times\left[\theta_{2 y} w^{l}, \theta_{2 y} E(w)\right]$, which is compact. It is easy to show that $\Phi$ maps $K$ into itself and is continuous. ${ }^{12}$ Thus $\Phi$ has a fixed point. Moreover, we can rewrite $\phi^{n}$ and $\phi^{u}$ as

$$
\begin{aligned}
\phi^{n}\left(w^{u}, P^{n}, P^{u}\right)= & P^{n}+\left(1-\lambda^{n}\left(w^{u}, P^{n}, P^{u}\right)\right)\left(1\left[e^{n}\left(w^{u}, P^{n}, P^{u}\right) \leq 0\right] \theta_{2 y} v\right. \\
& \left.+1\left[e^{n}\left(w^{u}, P^{n}, P^{u}\right)>0\right] \theta_{y} 2 v-P^{n}\right) \\
\phi^{u}\left(w^{u}, P^{n}, P^{u}\right)= & P^{u}+\left(1-\lambda^{u}\left(w^{u}, P^{n}, P^{u}\right)\right)\left(1\left[e^{u}\left(w^{u}, P^{n}, P^{u}\right) \leq 0\right] \theta_{2 y} w^{l}\right. \\
+ & \left.+1\left[e^{u}\left(w^{u}, P^{n}, P^{u}\right)>0\right] \theta_{2 y} E(w)-P^{u}\right)
\end{aligned}
$$

Thus a fixed point of $\Phi$ implies: $w^{u}=w^{A},\left(1-\lambda^{n}\left(w^{u}, P^{n}, P^{u}\right)\right)\left(1\left[e^{n}\left(w^{u}, P^{n}, P^{u}\right) \leq\right.\right.$ $\left.0] \theta_{2 y} v+1\left[e^{n}\left(w^{u}, P^{n}, P^{u}\right)>0\right] \theta_{y} 2 v+P^{n}\right)=0$, and $\left(1-\lambda^{u}\left(w^{u}, P^{n}, P^{u}\right)\right)\left(1\left[e^{u}\left(w^{u}, P^{n}, P^{u}\right) \leq\right.\right.$ $\left.0] \theta_{2 y} w^{l}+1\left[e^{u}\left(w^{u}, P^{n}, P^{u}\right)>0\right] \theta_{2 y} E(w)+P^{u}\right)=0$.

Since the expressions $\left(1\left[e^{n}\left(w^{u}, P^{n}, P^{u}\right) \leq 0\right] \theta_{2 y} v+1\left[e^{n}\left(w^{u}, P^{n}, P^{u}\right)>0\right] \theta_{y} 2 v-P^{n}\right)$ and $\left(1\left[e^{u}\left(w^{u}, P^{n}, P^{u}\right) \leq 0\right] \theta_{2 y} w^{l}+1\left[e^{u}\left(w^{u}, P^{n}, P^{u}\right)>0\right] \theta_{2 y} E(w)-P^{u}\right)$ are never equal to zero, we must have $\left(1-\lambda^{n}\left(w^{u}, P^{n}, P^{u}\right)\right)=0$ and $\left(1-\lambda^{u}\left(w^{u}, P^{n}, P^{u}\right)\right)=0$. This is only possible if $e^{n}\left(w^{u}, P^{n}, P^{u}\right)=e^{u}\left(w^{u}, P^{n}, P^{u}\right)=0$.

We thus have that

$$
w^{u}=w^{A}\left(w^{u}, P^{n}, P^{u}\right), \quad y_{s}^{u}\left(w^{u}, P^{n}, P^{u}\right)=y_{d}^{u}\left(w^{u}, P^{n}, P^{u}\right), \quad y_{d}^{n}\left(w^{u}, P^{n}, P^{u}\right)=y
$$

\footnotetext{
${ }^{12}$ Observe that $\left(1-\lambda^{i}\left(w^{u}, P^{n}, P^{u}\right)\right)=0$ at points where $e^{i}\left(w^{u}, P^{n}, P^{u}\right)=0$ which are the points of discontinuity for the expression multiplying $\left(1-\lambda^{i}\left(w^{u}, P^{n}, P^{u}\right)\right)$.
} 


\section{References}

Akerlof, G. (1970). "The Market for Lemons: Qualitative Uncertainty and the Market Mechanism." Quarterly Journal of Economics, 84, 488-500.

Kim J.-C. (1985) "The Market for Lemons Reconsidered: a Model of the Used Car Market with Asymmetric Information." American Economic Review, 75, 836-843.

Wilson, C. (1980). "The Nature of Equilibrium in Markets with Adverse Selection." Bell Journal of Economics, 11, 108-130. 

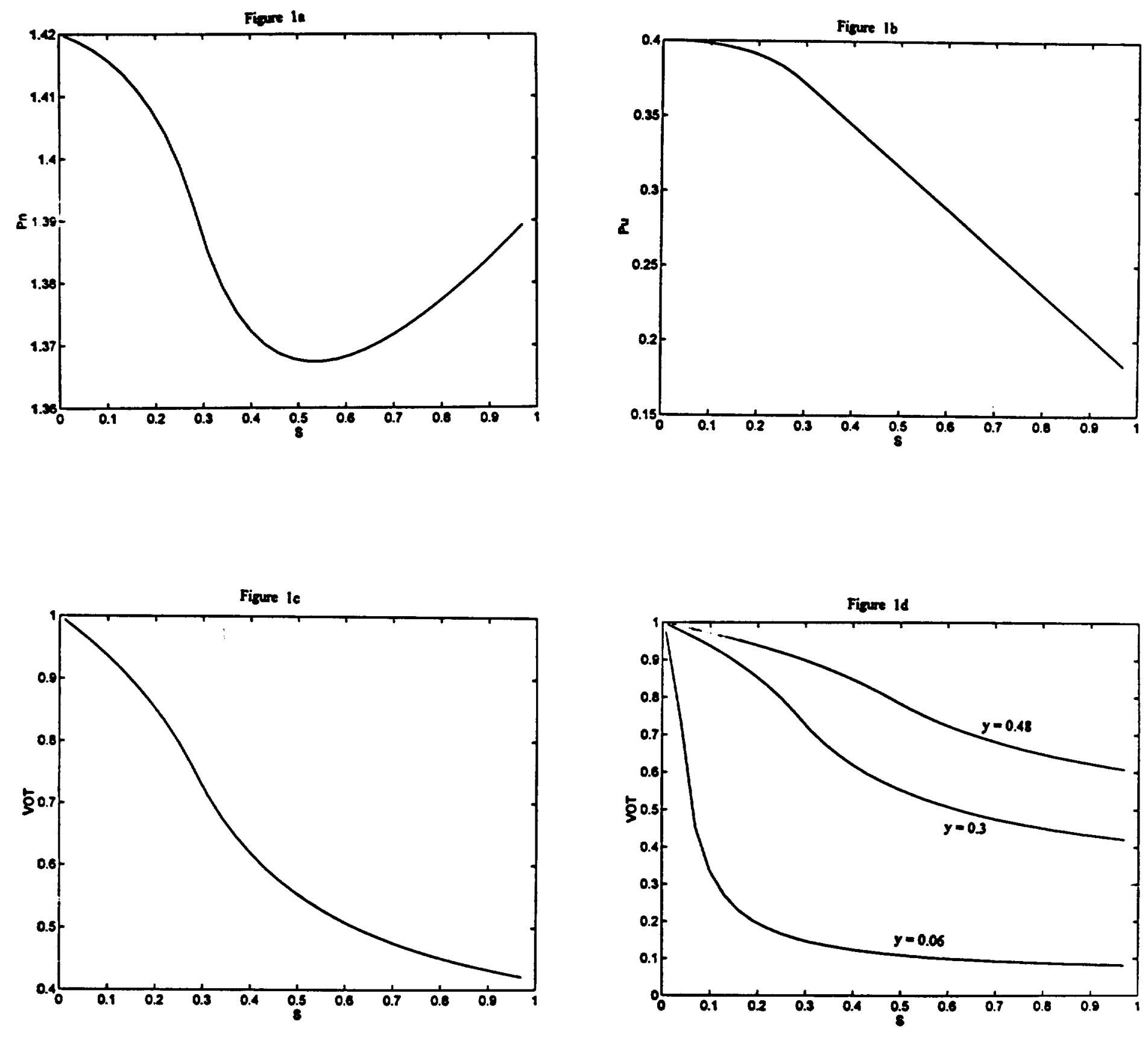

$$
v=2, \delta=0.8, y=0.3
$$


Figure 2a

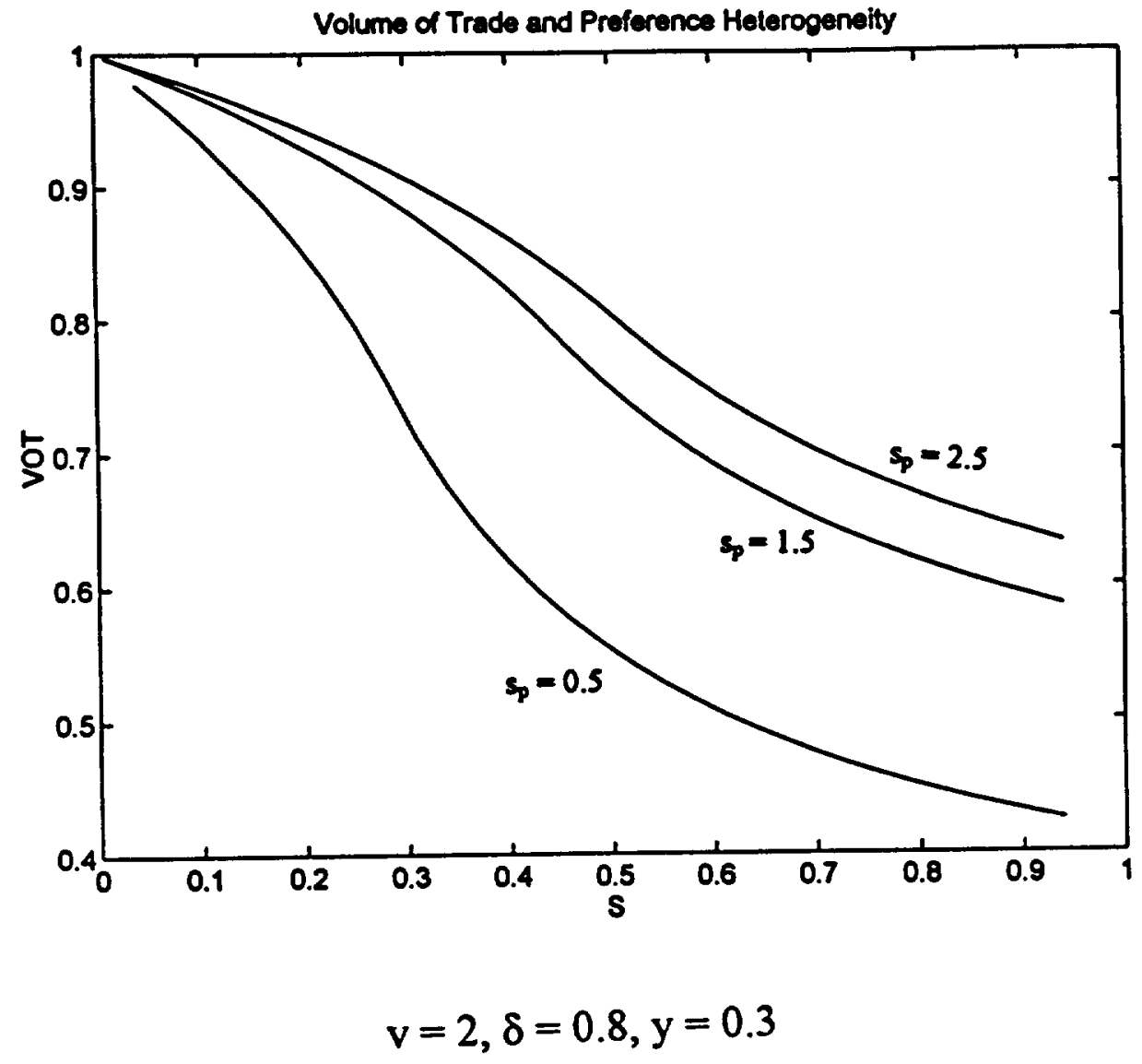

Figure $2 b$

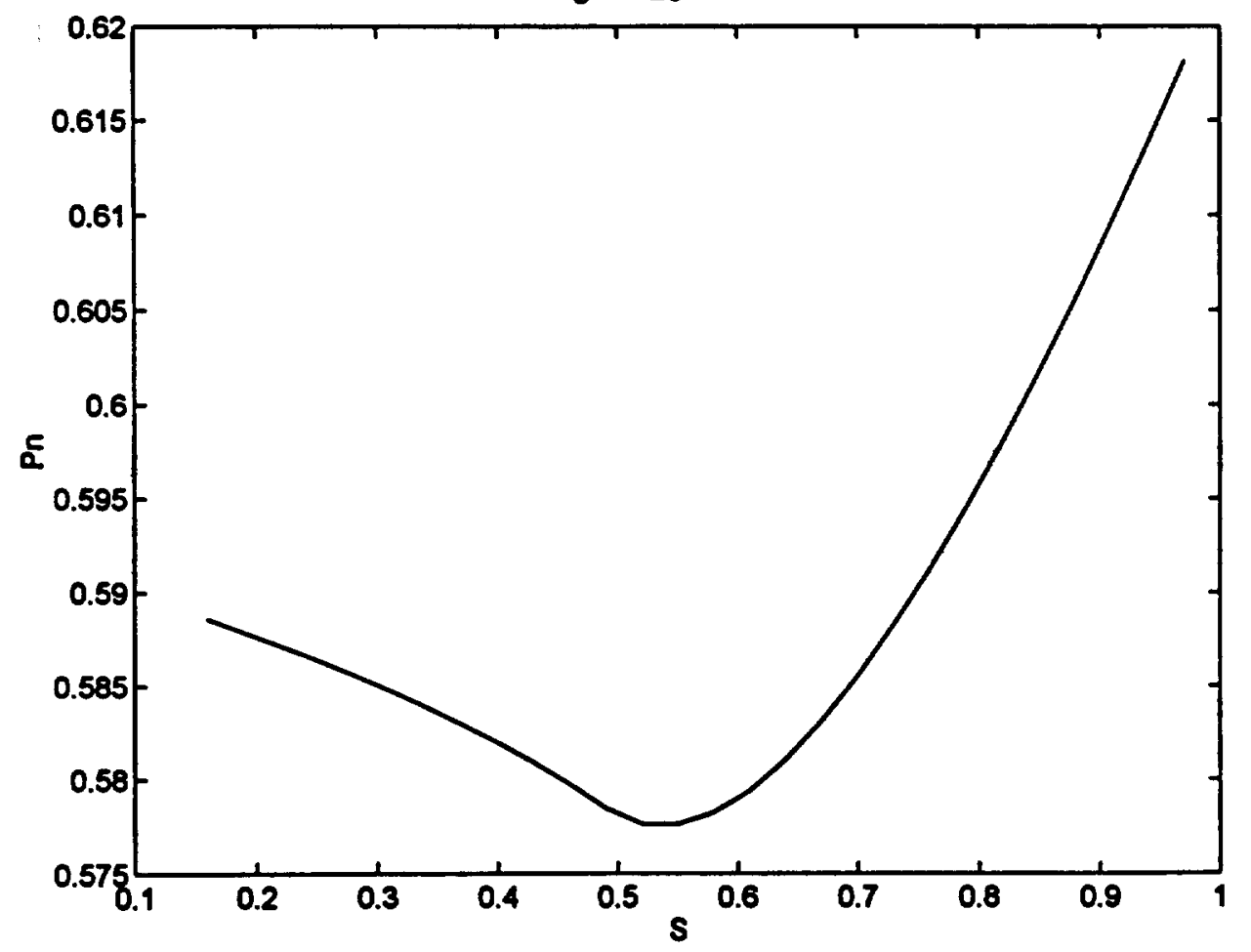

$$
v=2, \delta=0.8, y=0.45
$$


Fipe 30

Prions ef Now Cooch

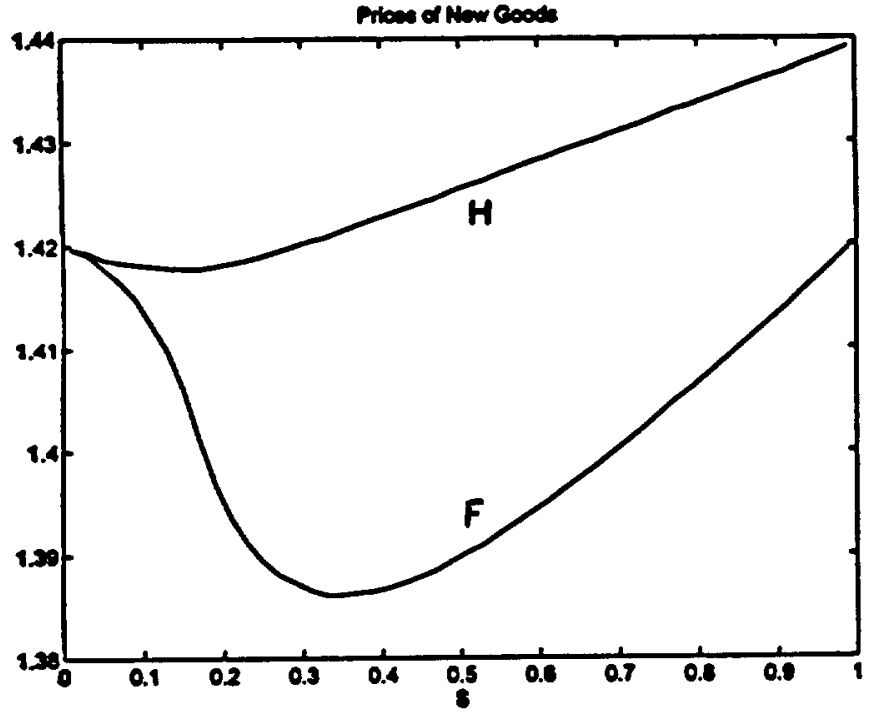

Fian

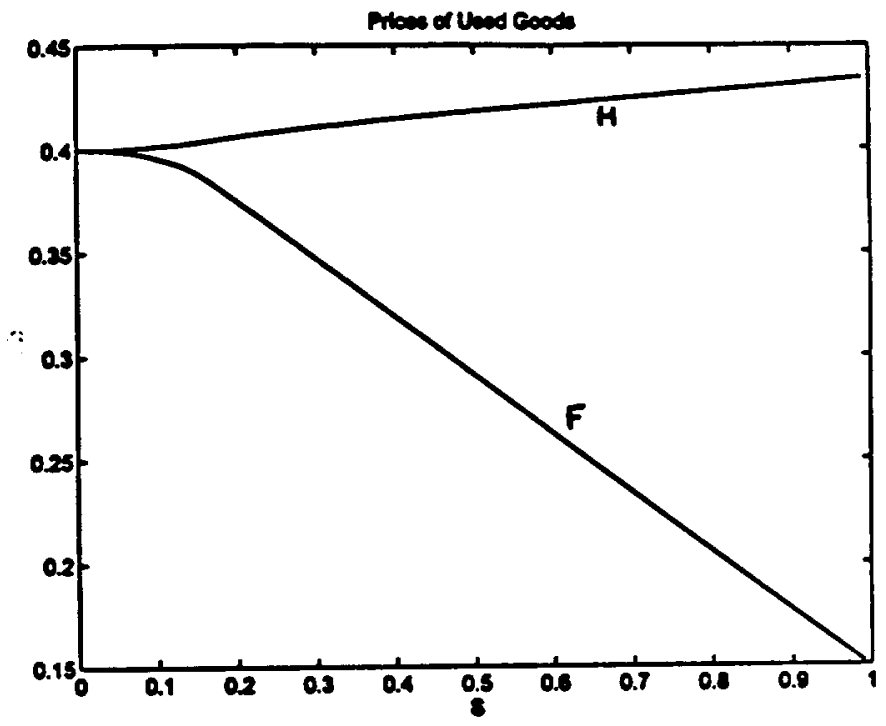

Figure 30

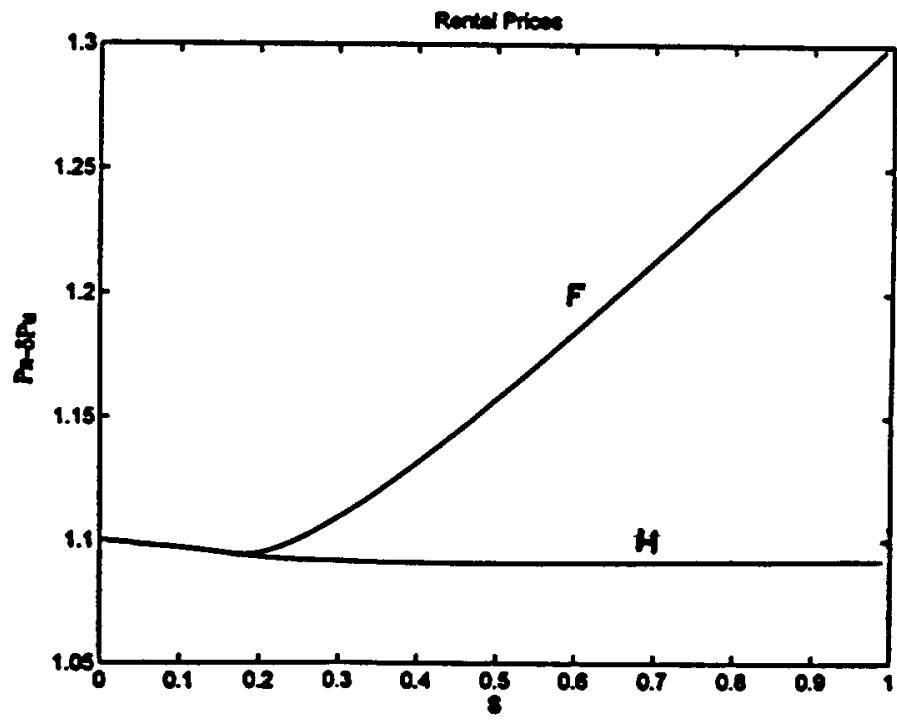

$v=2, \delta=0.8, y_{A}=y_{B}=0.15$ 